\title{
Low-temperature severe plastic deformation of pure magnesium
}

\author{
D. A. Komkova ${ }^{\dagger}$, O. V. Antonova, V. N. Petrova, A. Yu. Volkov \\ †komkova_d@imp.uran.ru
}

M. N. Miheev Institute of Metal Physics UB RAS, 18 S. Kovalevskaya St., Yekaterinburg, 620108, Russia

In this paper, the microstructure and texture of pure magnesium after rolling at low temperatures have been investigated. Pre-deformed magnesium in the form of a plate with the thickness of $1 \mathrm{~mm}$ was rolled at room and cryogenic temperatures down to foils with $150 \mu \mathrm{m}$ thickness. The true strain was $\varepsilon \sim 1.9$. Methods of X-ray diffraction, scanning electron microscopy with electron backscattering diffraction analyses (EBSD-analysis) and transmission electron microscopy have been used to investigate the structure and texture of the magnesium foils. In the initial state, the plate has a weakened basal texture and fine-grained structure. It was shown that the basal texture (0001) became stronger during rolling regardless of the deformation temperature. In all cases, the structure was heterogenic and consisted of large recrystallized grains with preferred basal orientation and smaller (sub)grains. However, it was noted that the room-temperature rolling led to an increase of the fraction of large grains, and lower deformation temperature prevents an active grain growth. The change of the number fraction of low-angle and high-angle boundaries could point on different lead mechanisms during deformation. At room-temperature rolling, there is the predominance of slip processes and dynamic recrystallization. As for at cryo-deformation, the twinning is more active and the dislocation slip could be suppressed for a while.

Keywords: magnesium, microstructure, texture, severe plastic deformation, electron microscopy.

\section{Introduction}

Magnesium and its alloys have high strength-to-weight and stiffness-to-weight ratios, good damping characteristics, low volume weight. The use of magnesium alloys can significantly reduce the weight of the overall structures of vehicles, save energy. Due to its chemical activity and high biocompatibility, magnesium or its alloys in ultra-fine form can be used to create new more powerful current sources or health monitoring sensors in transient electronics, or to produce thin membranes for the filtration of liquids and gases [1-3].

However, the plasticity of magnesium alloys at low temperatures is poor. At room temperature, the deformation of magnesium takes place mainly due to the basal slip. Pyramidal and prismatic slip systems become active at temperatures above $150^{\circ} \mathrm{C}[4,5]$. The deformation of magnesium at low temperature leads to the formation of strong (0001) basal texture. It causes an anisotropy of mechanical properties and cracking of the metal.

The formation of ultrafine-grained or nanocrystalline structure in metals by severe plastic deformation (SPD) leads to a significant improvement in plasticity and strength $[6,7]$. However, deformation by the most of SPD-methods is performed at high temperatures [8-10].

Earlier $[11,12]$ we have developed a new SPD-method called lateral extrusion. The method allows one to successfully achieve a high strain of magnesium. As a result of deformation, 1-mm magnesium plates were obtained and then rolled down to foils of various thicknesses at room temperature. At the end of [11], we announced experiments of Mg-cryodeformation. In $[13,14]$ we showed the impact of the texture of initial Mg-workpieces on structure, texture and mechanical properties of obtained plates. Based on previous papers, a plate with better qualities was choosen for rolling both at room and cryogenic temperatures.

The aim of this work is to investigate the structure and texture of foils obtained by rolling of pure magnesium at room and cryogenic temperatures.

\section{Materials and methods}

Pre-deformed pure magnesium (99.9\%) in a form of 1-mm plate was used as an initial material. The plate was obtained by lateral extrusion at room temperature [11-14].

Symmetric rolling of a 1-mm plate was performed by a laboratory rolling mill. The diameter of the rolls was $80 \mathrm{~mm}$ and the speed of rotation did not exceed 0.5 revolutions per second. The samples were rolled down to the thickness of $150 \mu \mathrm{m}$ at room temperature (room rolling) and at $-100^{\circ} \mathrm{C}$ (cold rolling) for 15 passes. To perform the deformation at $-100^{\circ} \mathrm{C}$ a sample was placed between the plates made of stainless steel. Then this "assembly" was cooled by dipping in liquid nitrogen for $30 \mathrm{sec}$ before each rollingpass. True strain $(\varepsilon)$ after rolling is 1.9 .

The microstructure and texture were investigated using $\mathrm{X}$-ray diffraction (XRD), transmission electron microscopy (TEM) and the electron backscatter diffraction (EBSD) analysis using a scanning electron microscope (SEM). XDR was performed by a diffractometer Rigaku DMAX 2200. 
In $\mathrm{XRD}$, the method of continuous shooting at a rate of $4 \%$ min was used, and the radiation of $\mathrm{Cu}_{\mathrm{Ka}}$ was monochromatized by a graphite single crystal. JEM $200 \mathrm{Cx}$ electronic microscope was used for TEM. EBSD-analyses were performed by a scanning microscope QUANTA 200 FEI with additional equipment for carrying out the texture analysis of samples. Kikuchi-patterns were automatically indicated by the TSL OIM data collection program (OIM - Orientation Imaging Microscopy). Data processing was performed by TSL OIM analysis software. During EBSD-analysis, the following parameters were chosen for all samples: the working distance of 10 , the magnification of 5000 and the scanning step of $0.35 \mu \mathrm{m}$. The as-obtained EBSD-maps were subjected to clean-up procedures involving a grain tolerance angle of $5^{\circ}$ and minimum grain size of three pixels. Legends for EBSD-orientation maps are presented in each figure near to map. In pole figures (PF), RD and TD correspond to rolling and transverse directions, respectively, and the normal direction (ND) is perpendicular to the RD-TD-plane.

The TEM-samples were produced by means of mechanical grinding and polishing followed by electrolytic polishing in a solution containing $20 \%$ of nitric acid and $80 \%$ of ethyl alcohol at $1 \mathrm{~V}$ at $0^{\circ} \mathrm{C}$. All the specimens were prepared at room temperature. To prepare the samples for EBSD-analysis, they were polished to a mirror surface. The electropolishing was done with a solution of $80 \%$ ethyl alcohol, $10 \%$ glycerine, $8 \%$ nitric acid and $2 \%$ acetic acid. The operating voltage was about $1 \mathrm{~V}$ at $0^{\circ} \mathrm{C}$. The samples were washed in ethyl alcohol and distilled water.

\section{Results}

The results of XRD-analysis are presented in Fig. 1.

A strong peak (0001) is observed in the initial 1-mm plate with the background of different lines of other planes (Fig. 1, line 1). However, the intensities of reflection lines of different planes are strong enough to assume that the texture (0001) is slightly weakened by a large number of grains with different orientations. The low-temperature rolling leads to the formation of the sharper texture (0001). The peak intensity (0001) is noted to be growing and the other lines are significantly decreasing (Fig. 2, lines 2,3).

Microstructure and texture of the 1-mm plate and after low-temperature rolling are presented in Figs. 2-4.

In the 1-mm plate (Fig. 2), a heterogenic bimodal structure is observed. Large elongated grains are in the matrix of smaller crystallites or substructure (Fig. 2a,b). Large grains demonstrate highly curved boundaries. During TEM-investigation, areas of fragmented microstructure are observed quite often. The volume fraction of ultrafine grains with the size about $1 \mu \mathrm{m}$ is approximately 0.5 (Fig. $2 \mathrm{~d}$ ). As for texture, most grains with the size of about 5-15 $\mu \mathrm{m}$ predominantly have a basal orientation (0001) or close to it while smaller ones show significant deviations from the basal planes (more than $15^{\circ}$ ) (Fig. $2 \mathrm{c}$ ). The high-angle boundaries exhibit two peaks corresponding to $38^{\circ}$ and $86^{\circ}$. These peaks can be associated with the presence of double twins on $\{10 \overline{1} 1\}-\{10 \overline{1} 2\}$ and compression twins on $\{10 \overline{1} 2\}$ with misorientation of $38^{\circ}$ and $86^{\circ}$ around $\langle 1 \overline{1} 20\rangle$,

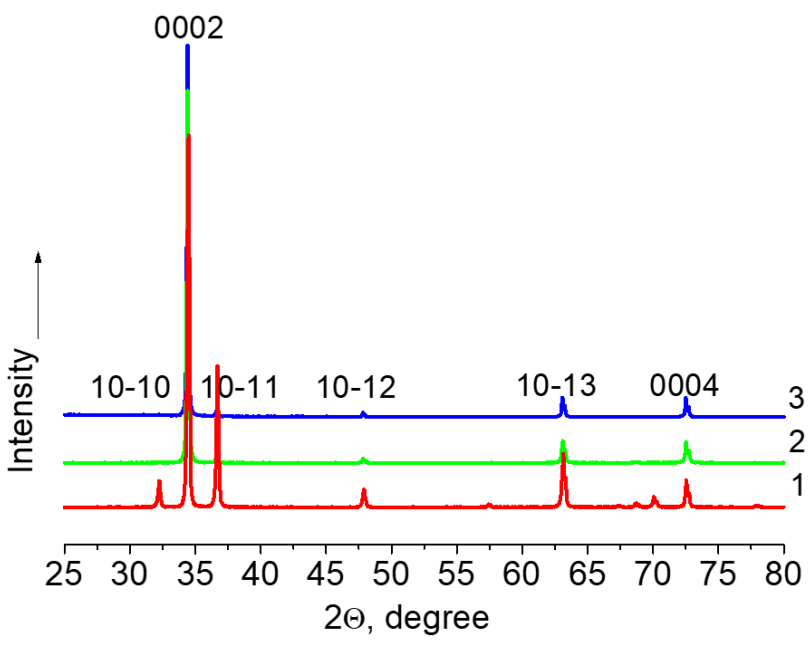

Fig. 1. (Color online) Diffraction patterns of magnesium: 1-mm plate (1); after room-rolling up to $150-\mu \mathrm{m}$ foil (2); after cold-rolling up to $150-\mu \mathrm{m}$ foil (3).

respectively [15]. Twin boundaries could be formed during the pre-deformation by lateral extrusion.

Room rolling (Fig. 3) resulted mainly in the grains growth. The average grain size is $6.9 \mu \mathrm{m}$ based on EBSD-analysis. The number fraction of ultrafine grains decreased down to $0.1-0.2$, and small crystallites mostly form at large grain boundaries (Fig. 3a,c). Such a "necklace"-structure usually indicates on the development of dynamic recrystallization processes [16-19]. It should be noted that during TEM-studies, we observed substructure areas with (sub)grain sizes up to $1 \mu \mathrm{m}$ more often than during EBSD. Based on TEM, the average grain size is about $6 \mu \mathrm{m}$. Inside some large grains, high dislocation density is detected presented by complicated dislocation configurations (Fig. 3 a). The PF (0001) are visibly changed in comparison to the PF (0001) in the initial state (Fig. $3 \mathrm{~d}$ ). After room rolling, the basal pole distribution is asymmetrical around ND and the intensity of pole (0001) is higher (20 versus 10 (Fig. $2 \mathrm{~d}$ )). The misorientation angle distribution shows a strong increase of the fraction of LABs (almost in 2.5 times). There is also a small peak around $38^{\circ}$ however, in comparison with LABs, it could be considered as a background (Fig. $3 \mathrm{~d}$ ).

Cold rolling of Mg-plate down to the $150-\mu \mathrm{m}$ foil (Fig. 4) leads to a bimodal structure. In a comparison to the structure of the initial plate, in this case the structure seems to be more uniform. At the same time, the general view of the structure remains similar: large recrystallized grains adjoined smaller ones (Fig. $3 \mathrm{a}, \mathrm{b}, \mathrm{c}$ ). The average grain size is about $3 \mu \mathrm{m}$. The number fraction of $1-\mu \mathrm{m}$ grains is not changed significantly (versus Fig. 2) and remains about 0.5. The (0001) pole figure demonstrates the different way of texture evolution. The PF resembles the double basal texture of the magnesium sheet during cold rolling [17]. The pole intensities are mainly spread along the RD (Fig. 3d). LABs number fraction decreases during cold rolling and differs from that in the room rolled foil ( 5 times less, Fig. 4 d). As for HABs, there are two peaks near $38^{\circ}$ and $86^{\circ}$, corresponding to double twinning and compression, on $\{10 \overline{1} 1\}-\{10 \overline{1} 2\}$ and $\{10 \overline{1} 2\}$, respectively. It is should be noted that during TEM the twin-looks-like structure was detected from time to time (Fig. 4, bottom). 


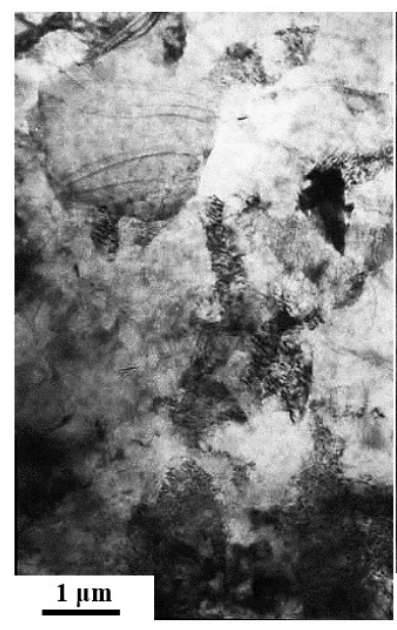

a

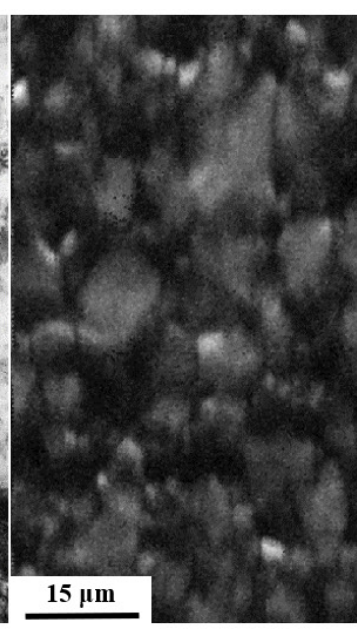

b

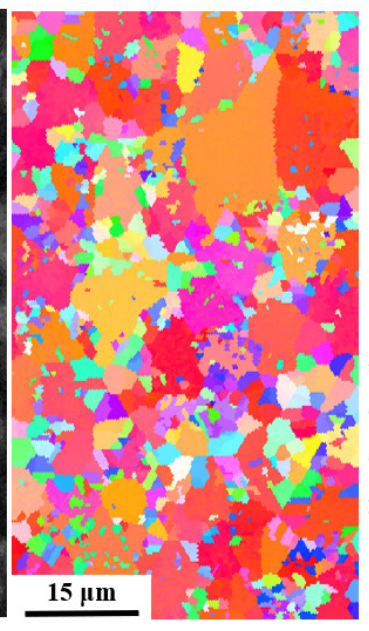

c
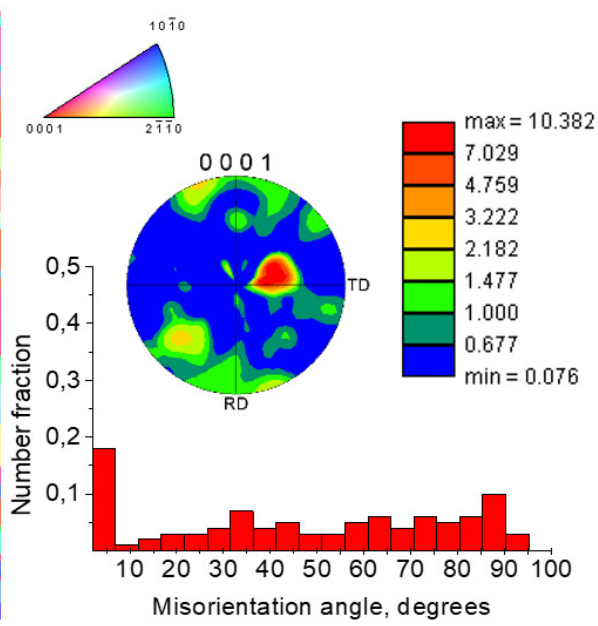

d

Fig. 2. (Color online) Microstructure and texture of magnesium pre-deformed by lateral extrusion (1-mm plate): TEM (a); EBSD-analysis (b, c); (0001) pole figure and misorientation angle distribution (d) (EBSD-data).

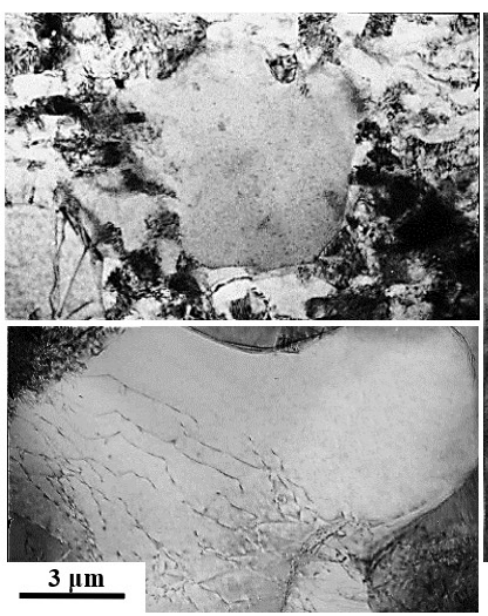

a

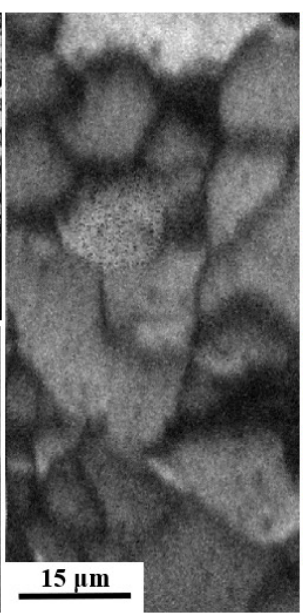

b

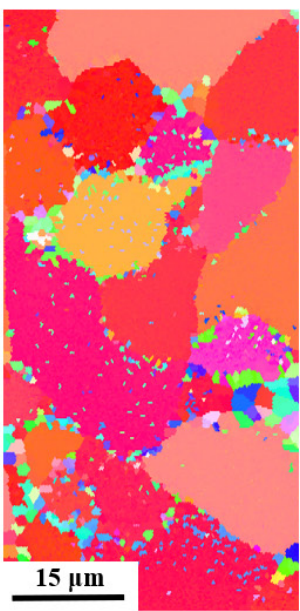

c

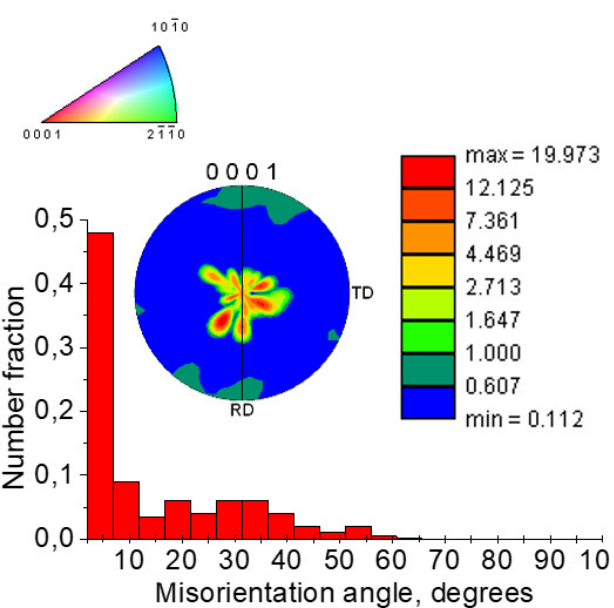

d

Fig. 3. (Color online) Microstructure and texture of the room rolled 150- $\mu \mathrm{m}$ foil of magnesium: TEM (a); EBSD-analysis (b,c); (0001) pole figure and misorientation angle distribution (d) (EBSD-data).

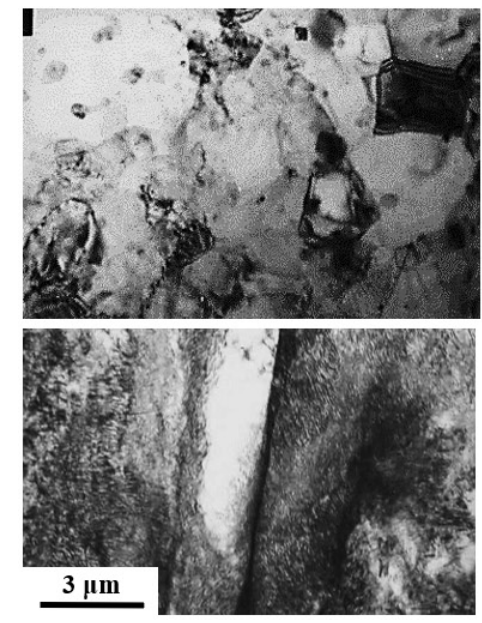

a

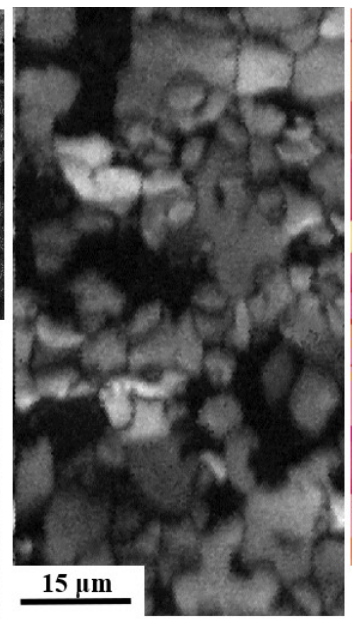

$\mathrm{b}$

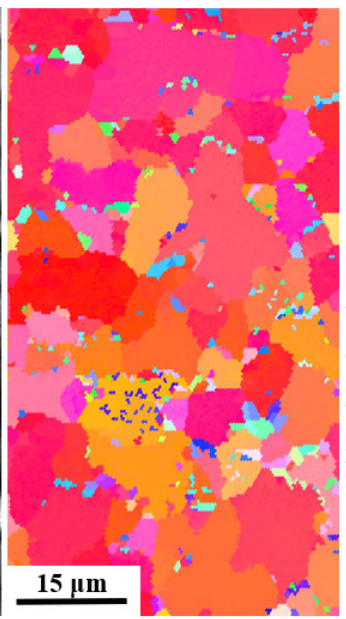

C

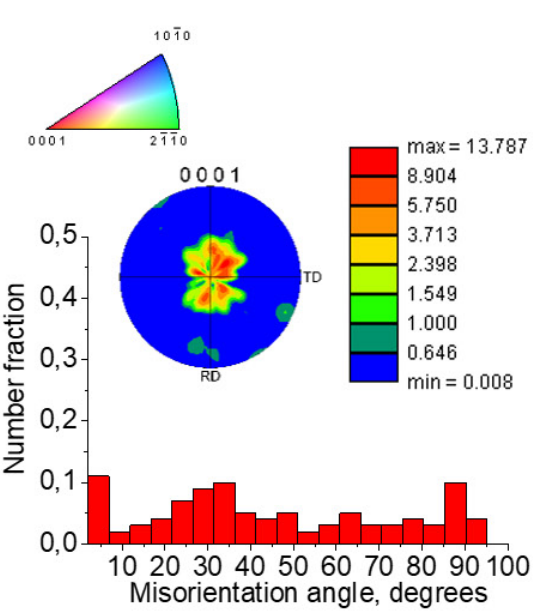

d

Fig. 4. (Color online) Microstructure and texture of the cold rolled 150- $\mu \mathrm{m}$ foil of magnesium: TEM (a); EBSD-analysis (b,c); (0001) pole figure and misorientation angle distribution (d) (EBSD-data). 


\section{Discussion}

In this paper, the results of studies on the structure and texture of pure magnesium after low-temperature rolling $(\varepsilon \sim 1.9)$ are presented. The pre-deformed pure magnesium in the shape of a 1-mm plate was used as the initial material. The texture of the initial material was weak and the structure consisted of a high fraction of grains of about $1 \mu \mathrm{m}$.

The high ductility of pre-deformed magnesium could be explained by the weak basal texture. It is known $[1-3,5,8,17]$ that the crystallographic texture has a significant effect on the deformation behavior of magnesium. The strong (0001) basal texture reduces the formability of magnesium, and the deformation becomes inhomogeneous and is characterized by the formation of shear bands [17]. The weak basal texture in the initial material could contribute to a large degree of deformation of magnesium. In [17], a magnesium sample with a weakened texture (0001) was selected as the material for rolling at room temperature, and it was rolled up to $80 \%$ strain without cracking. Authors suggested that in this case the development of the texture could not be achieved quickly owing to twinning or basic sliding due to the unfavorable (non-basic) orientation of the grains. Non-basal slip-systems could be involved and positively affect the ductility of the metal. The fine-grained structure of the initial sample of magnesium formed by SPD-method (lateral extrusion) is another reason for high ductility of pure hcp-metal $[7,10]$.

Despite the fact that, in our case, the initial sample satisfied all abovementioned conditions, the role of the geometric factor should be also noted. In $[11,12,14]$, the possibility of rolling a 1-mm plate with a sharp (0001) texture and a larger grain size to foils of different thicknesses was demonstrated. Moreover, additional rolling deformation experiments on plates with a thickness of more than $1 \mathrm{~mm}$ (for example, $1.5 \mathrm{~mm}$ ) revealed an inability to achieve a successful result without failure. It is obvious that the thickness parameter of the initial sample has a significant effect on the ductility of magnesium during rolling deformation. The phenomenon requires further detailed studies.

As for the microstructure during the rolling process, an unusual trend is noted. At room temperature, rolling of pure magnesium reduces the average grain size $[17,18]$. However, in our case, an increase of the grain size is noticeable after room rolling (Fig. 3). The average grain size is about $1 \mu \mathrm{m}$ in the 1-plate (the initial state), while in $150-\mu \mathrm{m}$ foil after roomtemperature rolling it is about $6 \mu \mathrm{m}$. The effect could be related to a recrystallization mechanism. In general, the formation of a "necklace" structure (Fig. 3) is typical of SPD-deformed magnesium and is explained by the dynamic recrystallization processes. The kinetics of dynamic recrystallization is determined by the mechanisms of plastic deformation including slip and twinning, as well as the migration of highangle boundaries $[16,19]$. Grains with highly curvilinear boundaries are most favorable for growth to minimize the energy of grain boundaries [20]. In the process of grain growth, large grains absorb their "small neighbors" through the process of grain boundaries migration and their merger. The schemes of deformation have an effect on the structure as well. True strain $(\varepsilon)$ during lateral extrusion is 3.9 by one pass. Such severe deformation and shear strains lead to a noticeable grain refinement. During lateral extrusion, the refinement of the structure could be successful due to the formation of shear bands. The accumulation and intersection of the bands can lead to additional grain-size refinement. As for coldrolling, the main mechanism is slip mainly along the basal plane and dynamic recrystallization. The rolling deformation is carried out in several passes. In this case, there is no shear deformation. As a result, dynamic recrystallization processes are more active, which leads to grain growth.

The change of the LABs and HABs number fractions in the structure after room rolling and cold rolling can indicate on a difference between the lead mechanisms of structure formation. At low temperatures, twinning is more active since a decrease of deformation temperature increases the critical resolved shear stress (CRSC) of slip [21]. In this case, the contribution of twinning to the evolution of the microstructure could be higher than at room-temperature deformation [22, 23]. Based on the results presented in Figs. $3 \mathrm{~d}$ and $4 \mathrm{~d}$, at room-rolling a high LABs fraction and the absence of twin misorientations could point at the predominance of slip processes and dynamic recrystallization. At cold-rolling, the HABs peaks (Fig. $4 \mathrm{~d}$ ) indicates the activation of twinning and some suppression of dislocation slip. It is known that the stresses required for the twin nucleation increase faster with a decrease of the grain size [21,24]. During cold-rolling (about $-100^{\circ} \mathrm{C}$ in this work), the high CRSC-values of the dislocation slip lead to smaller critical grain size, in which twinning is still possible. Intensive twinning along with dislocation slip could prevent the growth of grains. (Fig. 4 a, b, c).

\section{Conclusions}

The possibility of rolling at room and cryogenic temperatures of pre-deformed pure magnesium down to $150 \mu \mathrm{m}$ foils $(\varepsilon \sim 1.9)$ was shown. The structure and texture of magnesium foils were investigated. Based on the results, a high degree of rolling is achieved due to the fine-grained structure, weak basal texture and thickness of the initial sample (the geometric factor). During rolling at room temperature, the main mechanisms of deformation could be dislocation slip and dynamic recrystallization. Twinning processes play an important role during rolling at cryogenic temperatures.

Acknowledgements. This work was carried out within the framework of the State task (theme: Pressure no. AAAA-A18-118020190104-3) and the Russian Foundation for Basic Research (the RFBR project no. 18-33-00474).

\section{References}

1. B. L. Mordike, T. Ebert. Mater. Sci. Eng. A. 302, 37 (2001). Crossref

2. E. Doege, K. Droder. J. Mat. Proc. Tech. 115, 14 (2001). Crossref

3. B. Ch. Suh, M. Sh. Shim, K. S. Shin, N. J. Kim. Scr. Mat. 85, 1 (2014). Crossref

4. G.V. Raynor. The Physical Metallurgy of Magnesium and its Alloys. London-NewYork, Pergamon Press (1959) $531 \mathrm{p}$.

5. M. H. Yoo. Met. Trans. A. 12 (3), 409 (1981). Crossref 
6. K. K. Alaneme, E. A. Okotete, J. Magnes. Alloys. 5 (4), 460 (2017). Crossref

7. T. G. Langdon. Acta Mater. 61 (19), 7035 (2013). Crossref

8. Magnesium Technology (ed. by V. V. Joshi, J. B. Jordon, D. Orlov, N. R. Neelameggham). Cham, Springer (2019) 370 p. Crossref

9. R. B. Figueiredo, T. G. Langdon. J. Mat. Sci. 43 (23-24), 7366 (2008). Crossref

10. R. N. Harsha, V. M. Kulkarni, B. Satish Babu. Mat. Today: Proc. 5 (10), 22340 (2018). Crossref

11. O. V. Antonova, A.Yu. Volkov, B.I. Kamenetskii, D. A. Komkova. Mat. Sci. Eng. A. 651, 8 (2016). Crossref

12. A.Yu. Volkov, O.V. Antonova, B.I. Kamenetskii, I. V. Klyukin, D. A. Komkova, B.D. Antonov. Phys. Met. Metallogr. 117 (5), 518 (2016). Crossref

13. O.V. Antonova, A.Yu. Volkov, D.A. Komkova, B. D. Antonov. Mat. Sci. Eng. A. 706, 319 (2017). Crossref

14. D. A. Komkova, O. V. Antonova, A. Yu. Volkov. Phys. Met. Metallogr. 119 (11), 1120 (2018). Crossref

15. M. D. Nave, M. R. Barnett. Scripta Materialia. 51 (9), 881 (2004). Crossref
16. F. J. Humphreys, M. Hatherly. Recrystallization and related annealing phenomena. Oxford, Elsevier (2004) 658 p. Crossref

17. S. Suwas, G. Gottstein, R. Kumar. Mater. Sci. Eng. A. 471, 1 (2007). Crossref

18. Zh. Zeng, J.F. Nie, Sh.W. Xu, Ch. Davis, N. Birbilis. Nature communications. 8, 1 (2017). $\underline{\text { Crossref }}$

19. S. E. Ion, F. J. Humphreys, S. H. White. Acta. Met. 30 (10), 1909 (1982). $\underline{\text { Crossref }}$

20. I. A. Ovid'ko. Materials Physics and Mechanics. 8, 174 (2009).

21. M. A. Meyers, O. Vöhringer, V.A. Lubarda. Acta. mater. 49, 4025 (2001). Crossref

22. S. V. Zherebtsov, G.S. Dyakonov, A.A. Salem, S. P. Malysheva, G. A. Salishchev, S. L. Semiatin. Mater. Sci. Eng. A. 528 (9), 3474 (2011). Crossref

23. G.S. Dyakonov, S.V. Zherebtsov, M.V. Klimova, G. A. Salishchev. Phys. Met. Metallogr. 116 (2), 182 (2015). Crossref

24. Q. Yu, Zh. Shan, J. Li, X. Huang, L. Xiao, J.Sun, E. Ma. Nature. 463, 335 (2010). Crossref 